\title{
PERBANDINGAN SIFAT ANTIOKSIDAN PROPOLIS PADA DUA JENIS LEBAH (Apis mellifera dan Trigona sp.) DI MOJOKERTO DAN BATU, JAWA TIMUR, INDONESIA
}

\author{
Comparison of Antoxidant Properties of Propolis in Two Different Species of \\ Honey Bees (Apis mellifera and trigona sp.) in Mojokerto and Batu, \\ East Java, Indonesia \\ Djalal Rosyidi' ${ }^{1)}$, Lilik Eka Radiati ${ }^{1)}$, Sri Minarti ${ }^{1)}$, Mustakim1), Agus Susilo ${ }^{1)}$, Firman Jaya ${ }^{1)^{*}}$, Abdul Azis ${ }^{2)}$ \\ ${ }^{1)}$ Minat Teknologi Hasil Ternak, Fakultas Peternakan, Universitas Brawijaya, Jl. Veteran Malang, 65145, \\ Indonesia \\ 2) Alumni Fakultas Peternakan, Universitas Brawijaya, Jl. Veteran Malang, 65145, Indonesia \\ Email : firmanjaya@ub.ac.id
}

Diterima 30 Agustus 2018; diterima pasca revisi 25 Oktober 2018

Layak diterbitkan 30 Oktober 2018

\begin{abstract}
The current study provided a comparison the antioxidant activity, total phenolic and total flavonoid contents of propolis in two different types of honey bees and location. The material used for this research were propolis which was produced by different honey bees, namely Apis mellifera and Trigona sp in different location from Batu and Mojokerto. The method used was descriptive analysis. Findings suggested the maximum and minimum of antioxidant activity were obtained by propolis Trigona sp. from Mojokerto $(987.24 \mu \mathrm{g} / \mathrm{g}$ ) and propolis Trigona sp. from Batu $(166.25 \mu \mathrm{g} / \mathrm{g})$. The maximum and minimum of total flavonoid content were obtained by propolis Apis mellifera from Mojokerto $(1.990 \mathrm{mg} / \mathrm{g}$ ) and propolis Trigona sp from Mojokerto (1.000 $\mathrm{mg} / \mathrm{g}$ ). The maximum and minimum of total fenolic content were obtained by propolis Apis mellifera from Mojokerto $(21.980 \mathrm{mg} / \mathrm{g})$ and propolis Trigona sp from Mojokerto $(9.603 \mathrm{mg} / \mathrm{g})$. Propolis Apis mellifera from Mojokerto had a higher total flavonoids and phenolic content and Trigona sp. from Mojokerto had lowest of antioxidant activity, total flavonoids and total phenolics.
\end{abstract}

Key words : Antioxidant activity $I C_{50}$; flavonoid content; phenolic content; honey bee 


\section{ABSTRAK}

Tujuan penelitian ini adalah untuk membandingkan aktivitas antioksidan, kadar total fenolik dan kadar total flavonoid propolis dari dua jenis lebah dan lokasi yang berbeda. Materi yang digunakan pada penelitian ini adalah propolis yang dihasilkan dari Apis mellifera dan Trigona sp. yang digembalakan di dua lokasi yang berbeda yaitu Batu dan Mojokerto. Metode yang digunakan adalah analisis deskriptif. Aktivitas antioksidan tertinggi dan terendah ditunjukkan oleh propolis Trigona sp. asal Mojokerto (987,24 $\mu \mathrm{g} / \mathrm{g}$ ) dan propolis Trigona sp. asal Batu $(166,25 \mu \mathrm{g} / \mathrm{g})$. Kadar total flavonoid tertinggi dan terendah ditunjukkan oleh propolis Apis mellifera asal Mojokerto $(1,990 \mathrm{mg} / \mathrm{g})$ dan propolis Trigona sp. asal Mojokerto $(1,000 \mathrm{mg} / \mathrm{g})$. Kadar total fenolik tertinggi dan terendah ditunjukkan oleh propolis Apis mellifera asal Mojokerto (21,980 $\mathrm{mg} / \mathrm{g})$ dan propolis Trigona sp asal Mojokerto (9,603 mg/g). Propolis Apis mellifera asal Mojokerto memiliki kandungan total flavonoid dan fenoil tertinggi dan propolis Trigona sp. asal Mojokerto memiliki nilai aktivitas antioksidan, total flavonoid dan total fenolik terendah.

Kata kunci : Aktivitas antioksidan IC 50 ; flavonoid; fenolik; lebah madu

\section{PENDAHULUAN}

Lebah madu merupakan salah satu komoditi peternakan yang banyak diminati di Indonesia. Lebah madu adalah hewan yang menghasilkan berbagai macam produk yang bermanfaat untuk kesehatan manusia. Jenis lebah madu yang digunakan seperti Apis mellifera, Apis cerana, Apis dorsata dan Trigona sp. Apis mellifera dan Trigona sp. merupakan dua jenis lebah yang banyak diternakan karena mudah dalam sistem penggembalaannya.

Lebah madu jenis Apis mellifera memiliki keunggulan pada jumlah produksi madu yang tinggi dan tidak agresif atau lebih jinak. Lebah Trigona $s p$ merupakan lebah tidak bersengat dan memiliki keunggulan rasa madu yang khas lebih asam, harga madu yang lebih tinggi dan banyak diternakan secara tradisional. Jenis lebah tersebut dimanfaatkan untuk memberikan keuntungan bagi peternak.

Produk yang dihasilkan lebah berupa madu, polen, bee bread, royal jeli, propolis dan lilin lebah. Produk-produk tersebut memberikan keuntungan secara ekonomis untuk peternak dan kesehatan untuk konsumen. Hasil dari produk lebah banyak dikonsumsi untuk menjaga kesehatan manusia. Salah satu produk yang banyak dijual selain madu, memiliki khasiat yang baik untuk tubuh dan harga yang tinggi adalah propolis. Propolis merupakan suatu produk yang dihasilkan oleh lebah madu dan mengandung resin dan lilin lebah yang dikumpulkan dari sumber tanaman. Propolis dikumpulkan oleh lebah dari pucuk daun-daun yang muda untuk kemudian dicampur dengan air liurnya digunakan untuk menambal dan mensterilkan sarang. Kandungan dari propolis merupakan senyawa alami yang dikoleksi oleh lebah madu yang berasal dari kuncup dan eksudat tanaman dan pepohonan (Segueni et al., 2011).

Propolis banyak digunakan sebagai salah satu alternatif pengobatan alami pada saat ini. Komponen yang terkandung di dalamnya merupakan senyawa bioaktif yang dapat memberikan efek positif pada tubuh. Harga propolis yang cukup tinggi
*Corresponding author :

Firman Jaya

Email : firmanjaya@ub.ac.id

Minat Teknologi Hasil Ternak, Fakultas Peternakan,

Universitas Brawijaya, Jl. Veteran Malang, 65145,

Indonesia
How to cite :

Rosyidi, D., Radiati, L.E., Minarti, S., Mustakim., Susilo, A., Jaya, F., \& Azis, A. (2018). Perbandingan Sifat Antioksidan Propolis pada Dua Jenis Lebah (Apis mellifera dan Trigona sp.) di Mojokerto dan Batu, Jawa Timur, Indonesia. Jurnal Ilmu dan Teknologi Hasil Ternak, 13 (2), 108-117 
dan memiliki khasiat yang baik untuk manusia menjadikannya salah satu produk yang memberikan keuntungan untuk peternak.

Senyawa bioaktif pada propolis kaya akan flavonoid dan fenoliknya (Segueni et al., 2011). Senyawa tersebut merupakan antioksidan yang dapat digunakan untuk melawan radikal bebas. Kandungan senyawa fenolik dan flavonoid propolis tergantung dari letak geografis dan jenis lebah tersebut (Chan et al., 2013). Perbedaan karakteristik dan jenis lebah akan mempengaruhi produk yang dihasilkan. Kemampuan lebah terbang dalam mencari makan akan mempengaruhi kualitas dari propolis. Kandungan yang terdapat pada propolis akan beragam karena lebah akan mengambil resin yang terdapat dipohon sekitar wilayah penggembalaan. Lokasi akan menentukan kandungan senyawa bioakif karena tumbuhan yang berada di setiap lokasi akan berbeda. Letak geografis yang berbeda pada suatu wilayah akan mempengaruhi jenis tanaman yang tumbuh di lingkungan tersebut.

Jenis tanaman dapat mempengaruhi kandungan bioaktif dari propolis. Menurut Juspawiza (2013), propolis asal Malang memiliki kandungan antioksidan lebih dari $500 \mu \mathrm{g} / \mathrm{g}$, sedangkan menurut Hariyanto (2017) bahwa kandungan senyawa fenolik pada propolis Apis mellifera yang dipelihara di kawasan Jawa Tengah yaitu sebesar $0,379 \mu \mathrm{g} / \mathrm{g}$, dan kandungan flavonoidnya sebesar $0,913 \mu \mathrm{g} / \mathrm{g}$. Komposisi kimia propolis sangat kompleks dan tergantung dari vegetasi lingkungan tempat pengumpulannya sehingga kandungan senyawa bioaktif propolis yang ada di Indonesia dapat berbeda-beda dan berbeda juga dengan propolis yang ada di negara-negara Eropa, Amerika dan lainnya. Sabir (2005) mengemukakan bahwa komposisi propolis sangat bervariasi dan erat hubungannya dengan jenis dan umur tumbuhan di mana propolis tersebut berasal dan umumnya propolis terdiri dari campuran resin dan getah 39-53\%, polifenol $1,2-17 \%$, polisakarida $2-3 \%$, lilin (wax) 19-35\%, dan bahan lain 8-12\% . Hasan et al. (2014) juga berpendapat bahwa senyawa bioaktif seperti fenolik, flavonoid dan antioksidan yang terkandung di dalam propolis memiliki manfaat sebagai antioksidan alami. Propolis Trigona $s p$. memiliki kandungan senyawa fenolik 104$498 \mu \mathrm{g} / \mathrm{g}$ dan flavonoid 0,405-129,265 $\mu \mathrm{g} / \mathrm{g}$.

Kandungan antioksidan $\mathrm{IC}_{50} 68,93-$ 4162, $61 \mu \mathrm{g} / \mathrm{g}$. Propolis yang ada saat ini masih belum memiliki standar nasional maupun internasional mengenai kandungan yang dimiliki propolis, sehingga diperlukan suatu informasi mengenai kandungan propolis. Informasi tersebut dapat digunakan sebagai pembanding ataupun data pendukung.

Sehubungan uraian di atas, maka penelitian mengenai perbedaan kandungan senyawa bioaktif propolis yang berasal dari dua jenis lebah madu yaitu Apis mellifera dan Trigona $s p$. serta lokasi yang berbeda perlu dilakukan. Tujuan penelitian ini untuk membandingkan aktivitas antioksidan, kadar total flavonoid dan kadar total fenolik propolis terbaik yang berasal dari dua jenis lebah madu (Apis mellifera dan Trigona $s p$.) dan dua lokasi yang berbeda.

\section{MATERI DAN METODE}

Penelitian ini dilakukan dengan menggunakan propolis yang berasal dari dua jenis lebah yang berbeda yaitu Apis mellifera dan Trigona sp. dan lokasi penggembalaan yang berbeda yaitu Batu dan Mojokerto. Sampel propolis didapatkan dari PT. Kembang Joyo Sriwijaya. Propolis diekstrak terlebih dahulu dengan metode maserasi. Hasil ekstraksi kemudian diuji kandungan bioaktifnya. Metode penelitian menggunakan metode deskriptif.

Data yang diperoleh merupakan data primer yang didapatkan langsung dari hasil laboratorium. Sampel propolis diambil berdasarkan jenis lebah dan lokasi penggembalaann. Hasil dari data primer ditabulasi dan dianalisis secara deskriptif 
untuk menggambarkan dan menjelaskan bagaimana hasil penelitian tersebut.

Bahan yang digunakan dalam penelitian ini adalah raw propolis dan etanol 70\%, metanol, larutan DPPH $(1,1-$ diphenyl-2-picrylhydrazyl), Folinciocalteau, natrium karbonat, kuersetin, $\mathrm{NaNO}_{2}, \mathrm{AlCl}_{3}$, dan $\mathrm{NaOH} . \quad$ Oven, inkubator, spektofotometer UV-VIS (Labomed INC), vortex (IKA), orbital shaker (Daihan Scietific), gelas ukur $5 \mathrm{~mL}$ dan $10 \mathrm{~mL}$ (Pyrex), timbangan analitik (Denver M 310 USA), kertas saring whatman No.1, pipet tetes (Iwaki), beker gelas $100 \mathrm{~mL}$ dan $1000 \mathrm{~mL}$ (Pyrex), tabung reaksi (Pyrex), dan corong kaca (Supertek).

Variabel yang diteliti dalam penelitian ini dilihat dari beberapa parameter yaitu aktivitas antioksidan $\mathrm{IC}_{50}$, kadar total flavonoid, dan kadar total fenolik.

\section{Ekstraksi Propolis}

Ekstraksi dilakukan dangan metode maserasi menggunakan etanol $70 \%$. Propolis direndam minimal tiga hari diruang gelap. Perbandingan sampel dengan pelarut yaitu 1:10 (Krell, 1996).

\section{Penentuan Aktivitas Antioksidan IC $_{50}$}

Kadar Antioksidan diketahui dengan menggunakan DPPH. Absorbansi larutan diukur dengan menggunakan spektrofotometer dengan panjang gelombang $517 \mathrm{~nm}$. Warna DPPH akan berubah dari berwarna ungu hingga menjadi kuning seiring dengan penambahan antioksidan.

\section{Penentuan Uji Flavonoid}

Total flavonoid diukur dengan kuarsetin equivalen. Larutan dibaca pada $415 \mathrm{~nm}$ pada spektrofotometer. Kuersetin merupakan flavonoid golongan flavonol yang dapat dideteksi dengan pereaksi $\mathrm{AlCl}_{3}$, reaksi tersebut akan membentuk ikatan komplek dengan gugus hidroksil dari senyawa flavonoid. Hasil absorbansi diekspresikan hasilnya sebagai sampel $\mathrm{mg}$ quercetin $(\mathrm{QE}) / \mathrm{g}$

\section{Penentuan Uji Fenolik}

Total Fenolik ditentukan berdasarkan metode Folin-Ciocalteau dan dinyatakan dalam mg Gallic Acid Equivalent (Ekuivalen Asam Galat). Folin-Ciocalteau merupakan reagen yang dapat membentuk larutan kompleks dengan fenol yang terkandung. Larutan dibaca $725 \mathrm{~nm}$ pada spektrofotometri. Hasil akhir akan diekspresikan dengan mg (GAE) /g.

\section{HASIL DAN PEMBAHASAN}

Aktivitas antioksidan $\mathrm{IC}_{50}$ merupakan konsentrasi senyawa antioksidan yang dibutuhkan untuk mengurangi radikal bebas sebanyak 50\%. Hasil aktivitas antioksidan didapatkan dari persentase inhibisi yang dihitung dengan perhitungan regresi linear. Hasil penelitian mengenai pengaruh perbedaan jenis lebah dan lokasi penggembalaan dapat dilihat pada Tabel 1 . Aktivitas antioksidan $\mathrm{IC}_{50}$ propolis terendah dihasilkan oleh lebah Trigona $s p$ asal Batu dengan nilai rataan $166,25 \mu \mathrm{g} / \mathrm{g}$, Apis mellifera asal Mojokerto 173,05 $\mu \mathrm{g} / \mathrm{g}$, Apis mellifera asal Batu 178,79 $\mu \mathrm{g} / \mathrm{g}$ dan tertinggi yaitu Trigona $s p$ asal Mojokerto dengan nilai rataan $987,24 \mu \mathrm{g} / \mathrm{g}$.

Hal ini menandakan bahwa untuk mengurangi radikal bebas sebesar $50 \%$ maka dibutuhkan 173,05 $\mu \mathrm{g} / \mathrm{g}$ untuk propolis Apis mellifera asal Mojokerto dan 987,24 $\mu \mathrm{g} / \mathrm{g}$ untuk propolis Trigona $s p$ asal Mojokerto. Kandungan antioksidan yang terdapat pada propolis dipengaruhi oleh kandungan fenolik (Marghitas et al., 2011). Semakin tinggi nilai kandungan fenolik maka semakin rendah nilai $\mathrm{IC}_{50}$ yang dimiliki.

Komponen flavonoid (seperti krisin atau kuersetin) dan asam organik (seperti asam firulat atau asam kafeat) merupakan senyawa aktif yang dapat bersifat antioksidan, yang ditunjukkan oleh adanya kemampuan mereduksi radikal bebas DPPH (Hasan dkk. 2013). 
Tabel 1. Nilai rataan aktivitas antioksidan $\mathrm{IC}_{50}$ propolis

\begin{tabular}{ccc}
\hline Jenis Lebah & Lokasi & Aktivitas Antioksidan $\mathrm{IC}_{50}(\mu \mathrm{g} / \mathrm{g})$ \\
\hline Apis mellifera & Batu & $178,79 \pm 1,70$ \\
& Mojokerto & $173,05 \pm 0,53$ \\
Trigona $s p$ & Batu & $166,25 \pm 0,42$ \\
& Mojokerto & $987,24 \pm 4,03$ \\
\hline
\end{tabular}

Kapasitas antioksidan suatu bahan dipengaruhi oleh komponen-komponen di dalam bahan tersebut yang mampu beraktivitas untuk menghambat terjadinya oksidasi (Ariviani dan Parnanto, 2013). Nilai yang lebih rendah menandakan bahwa Propolis Apis mellifera memiliki kandungan antioksidan yang terbaik.

Kandungan antioksidan yang dihasilkan dari kedua jenis lebah tersebut tergolong lemah. Menurut Junita dkk. (2017), menyatakan bahwa suatu zat dikatakan memiliki aktivitas antioksidan lemah jika nilai $\mathrm{IC}_{50}$ dari senyawa tersebut lebih dari $150 \mu \mathrm{g} / \mathrm{ml}$ atau setara dengan 150 ppm. Marghitas dkk. (2011), di dalam penelitiannya mendapatkan nilai $\mathrm{IC}_{50}$ terendah sebesar $440 \mu \mathrm{g} / \mathrm{g}$. Wang, Sankarapandian, Cheng et al. (2016) mendapatkan hasil antioksidan sebesar 25,7-476,5 $\mu \mathrm{g} / \mathrm{g}$ yang didapatkan dari 20 tempat berbeda di Korea Selatan. Laskar et al. (2010) di dalam penelitiannya mendapatkan kandungan antioksidan $\mathrm{IC}_{50}$ yang berasal dari India memiliki nilai sebesar $70 \mu \mathrm{g} / \mathrm{g}$. Kandungan dari antioksidan tersebut memiliki perbedaan yang disebabkan karena perbedaan geografis atau asal lebah dan waktu dalam pemanenannya.

Aktivitas antioksidan tersebut dipengaruhi oleh nilai flavonoid yang terkandung didalam propolis. Flavonoid adalah salah satu komponen senyawa fenolik yang merupakan antioksidan alami yang berasal dari tumbuhan. Tumbuhan yang hidup di lokasi penggembalaan akan mempengaruhi kandungan flavonoid yang merupakan antioksidan alami di dalam propolis.

\section{Total Flavonoid}

Hasil penelitian mengenai pengaruh perbedaan jenis lebah dan lokasi penggembalaan dapat dilihat pada Tabel 2

Tabel 2. Nilai rataan flavonoid propolis

\begin{tabular}{ccc}
\hline Jenis Lebah & Lokasi & Flavonoid $(\mathrm{mg} / \mathrm{g}) \pm \mathrm{SD}$ \\
\hline Apis mellifera & Batu & $1,808 \pm 0,086$ \\
& Mojokerto & $1,990 \pm 0,038$ \\
Trigona $s p$ & Batu & $1,789 \pm 0,053$ \\
& Mojokerto & $1,000 \pm 0,033$ \\
\hline
\end{tabular}

Kandungan total flavonoid tertinggi dihasilkan oleh propolis lebah Apis Mellifera asal Mojokerto sebesar 1,990 $\mathrm{mg} / \mathrm{g}$, Apis mellifera asal Batu 1,808 mg/g, Trigona $s p$ asal Batu $1,789 \mathrm{mg} / \mathrm{g}$ dan terendah oleh Trigona $s p$ asal Mojokerto $(1,395 \mathrm{mg} / \mathrm{g})$. Hasil tersebut menunjukan bahwa perbedaan jenis lebah mempengaruhi kandungan flavonoid dari propolis. Kandungan senyawa flavonoid yang dihasilkan dari kedua jenis lebah tersebut lebih tinggi dibandingkan dengan hasil penelitian yang dilakukan Haryanto (2017), pada penelitiannya didapatkan 
$1,831 \mu \mathrm{g} / \mathrm{g}$ untuk propolis lebah Apis mellifera dan $0,129 \mathrm{mg} / \mathrm{g}$ propolis lebah Trigona sp. Hasan et al. (2014), melakukan penelitian terhadap lima sampel propolis yang didapatkan dari lima lokasi berbeda di Indonesia dengan hasil 0,024-0,046 mg/g. Senyawa flavonoid yang terkandung di dalam propolis tersebut jauh lebih rendah jika dibandingkan dengan propolis yang berasal dari negara lain. Wang et al. (2016) menyatakan bahwa propolis asal Cina, Korea, Australia dan Brazil memiliki nilai diatas 20,8-53 mg/g. Andradea et al. (2017) menyatakan bahwa kandungan falvonoid propolis yang berasal dari Brazil sebesar $55-91 \mathrm{mg} / \mathrm{g}$. Miguel et al. (2010) di dalam penelitiannya mendapatkan nilai kandungan flavonoid pada musim yang berbeda yaitu pada musim salju sebesar $1,10-1,71 \mathrm{mg} / \mathrm{g}$ dan pada musim semi sebesar 1,12-1,56 mg/g.

Kandungan flavonoid yang terdapat di dalam propolis dipengaruhi oleh asal tanaman sebagai bahan baku. Kompisisi kimia propolis tergantung pada kekhususan flora lokal yang berada di lokasi pengumpulan (Jaya, 2017). Tumbuhan yang paling banyak di lokasi penggembalaan adalah pohon pinus untuk wilayah Batu dan pohon mangga untuk wilayah Mojokerto. Kedua jenis tumbuhan tersebut memiliki senyawa bioaktif seperti flavonoid. Daun dan batang pinus memiliki banyak digunakan sebagai obat-obatan karena memiliki kandungan flavonoid dan fenolik (Arel dkk., 2016). Selain pohon pinus, pohon mangga memiliki kandungan flavonoid yang tinggi. Kulit pohon mangga memiliki kandungan flavonoid yang cukup banyak (Lukmandaru dkk., 2012)

Lokasi penggembalaan yang memiliki jenis tumbuhan sedikit maka akan mempengaruhi jumlah kandungan flavonoid di dalam propolis. Keterbatasan tumbuhan di wilayah penggembalaan berakibat pada sulitnya lebah dalam mencari makanan karena jangkauan terbang lebah yang berbeda.

Lokasi penggembalaan di Batu penyebaran pohon pinus cukup merata sedangkan lokasi penggembalaan di Mojokerto banyak dibatasi oleh persawahan. Keterbatasan inilah yang menyebabkan kandungan flavonoid pada propolis berbeda-beda. Selain keterbatasan tanaman disekitar penggembalaan, kemampuan terbang dari setiap lebah berbeda. Lebah Apis mellifera memiliki jangkauan terbang mencapai $5 \mathrm{~km}$ sehingga lebah mampu mencari pakan di tempat lain, sedangkan Trigona $s p$. hanya memiliki jangkauan terbang dengan radius $500 \mathrm{~m}$ sehingga lebah hanya intensif pada area sekitar sarang (Djajasaputra, 2010).

\section{Total Fenolik}

Nilai kandungan fenolik dari ekstrak propolis yang berasal dari dua jenis lebah yang berbeda mempunyai nilai yang beragam. Hasil penelitian mengenai perbedaan jenis lebah dan lokasi penggembalaan dapat dilihat pada Tabel 3.

Tabel 3. Nilai rataan fenolik propolis

\begin{tabular}{ccc}
\hline Jenis Lebah & Lokasi & Fenolik $(\mathrm{mg} / \mathrm{g})$ \\
\hline Apis mellifera & Batu & $11,003 \pm 0,732$ \\
& Mojokerto & $21,980 \pm 0,547$ \\
Trigona $s p$ & Batu & $15,170 \pm 0,159$ \\
& Mojokerto & $9,603 \pm 0,207$ \\
\hline
\end{tabular}

Nilai kandungan fenolik tertinggi terdapat pada ekstrak propolis dari lebah Apis mellifera asal Mojokerto dengan nilai $21,980 \mathrm{mg} / \mathrm{g}$, Trigona sp. asal Batu 15,170 mg/g, Apis mellifera asal Batu 11,003 mg/g dan ekstrak propolis dari lebah Trigona $s p$ asal Mojokerto lebih rendah yaitu 9,603 $\mathrm{mg} / \mathrm{g}$. Hasil yang diperoleh lebih tinggi 
dibandingkan dengan hasil penelitian Hariyanto (2017) pada ekstrak propolis dari lebah Trigona sp sebesar $0,104 \mathrm{mg} / \mathrm{g}$. Ekstrak propolis lebah Apis mellifera diperoleh lebih tinggi jika dibandingkan dengan penelitian Nugraheni (2016) di dalam Hariyanto (2017) sebesar 0, 379 $\mu \mathrm{g} / \mathrm{g}$, sedangkan ekstrak propolis Apis mellifera yang didapatkan dalam bentuk $\mu \mathrm{g}$ yaitu 15.170,38 $\mu \mathrm{g} / \mathrm{g}$. Keberadaan senyawa-senyawa fenolik dapat menentukan aktivitas antioksidan yang terdapat di dalam propolis (Indrawati dan Razimin, 2013).

Jika dibandingkan dengan propolis yang berada di luar negeri, total fenolik yang didapatkan terbilang rendah. Jug, et al. (2014) di dalam penelitiannya mendapatkan nilai total fenolik yang berkisar 160-359 mg/g. Miguel et al. (2010) melakukan penelitian di musim yang berbeda dan didapatkan kandungan flavonoid pada musim salju sebesar 3,92$8,60 \mathrm{mg} / \mathrm{g}$ dan pada musim semi 4,57-8,79 $\mathrm{mg} / \mathrm{g}$. Andrade et al. (2017) mendapatkan nilai fenolik sebesar 30-59 mg/g yang didapatkan dari propolis asal Brazil. Kandungan fenolik tergantung dengan lokasi, letak geografis dan sumber tanaman (Saric et al, 2012).

Perbedaan kandungan fenolik disebabkan karena sumber tanaman yang tersedia berbeda sehingga kandungan fenolik pun beragam. Tingginya kandungan flavonoid didalam suatu tanaman akan mempengaruhi kandungan fenolik. Beragamnya jenis tanaman disebabkan oleh lokasi yang digunakan pada saat penggembalaan memiliki letak geografis berbeda. Lokasi penggembalaan di Batu didominasi oleh tanaman pinus yang merata. Pinus banyak digunakan masyarakat sebagai bahan baku obat traditional dan dikembangkan dalam berbagai sediaan farmasi seperti kapsul (Arel dkk., 2016). Penggunaan pinus sebagai bahan baku obat karena pinus memiliki kandungan fenolik yang cukup tinggi. Lokasi penggembalaan di Mojokerto memanfaatkan pohon mangga sebagai sumber makanan lebah. Pohon mangga memiliki kandungan flavonoid dan fenolik yang tinggi, akan tetapi lokasi tersebut dibatasi oleh wilayah persawahan sehingga salah satu jenis lebah hanya mampu mencari makan di sekitar sarang.

Kemampuan lebah dalam mencari makanan dapat mempengaruhi kandungan fenolik dikarenakan jenis tanaman yang ditemukan terbatas oleh jarak terbang maksimal lebah. Jarak jangkauan terbang lebah Apis mellifera yang lebih jauh dari Trigona sp. memberikan keunggulan terhadap lebah tersebut dalam mencari makanan. Berbeda dengan Trigona sp. jarak jangkauan terbangnya yang pendek menyebabkan lebah tersebut hanya intensif mencari pakan di sekitar sarang (Djajasaputra, 2010).

\section{KESIMPULAN}

Propolis Apis mellifera asal Mojokerto memiliki kandungan total flavonoid dan total fenolik lebih tinggi $(1,990 \pm 0,038 \mathrm{mg} / \mathrm{g}$ dan $21,980 \pm 0,547$ $\mathrm{mg} / \mathrm{g}$ ) dibandingkan dengan Apis mellifera asal Batu dan Trigona sp. asal Batu dan Mojokerto, sedangkan nilai aktivitas antioksidan $\mathrm{IC}_{50}$ terbaik dimiliki oleh propolis Trigona $s p$. asal Batu yaitu 166,25 $\pm 0,42 \mu \mathrm{g} / \mathrm{g}$.

\section{UCAPAN TERIMA KASIH}

Peneliti mengucapkan terima kasih kepada Fakultas Peternakan Universitas Brawijaya yang telah mengadakan penelitian serta BOPTN yang telah mendanai penelitian ini

\section{DAFTAR PUSTAKA}

Andrade, J. K. S., Denadai, M., de Oliveira, C. S., Nunes, M. L., \& Narain, N. (2017). Evaluation of bioactive compounds potential \& antioxidant activity of brown, green \& red propolis from Brazilian northeast region. Food Research International, 
101(1),

$129-138$.

https://doi.org/10.1016/j.foodres.2017.08.066

Arel, A., Dira, \& Setiawati, A. (2016). Isolasi senyawa utama kulit batang tumbuhan pinus dari ekstrak etil asetat. Jurnal Ilmiah Kesehatan, 12(2), 60-66.

Arivianti, S., \& Parnanto, N. H. R. (2013). Kapasitas antioksidan buah salak (salacca edulis reinw) kultivar pondoh, nglumut \& bali serta korelasinya dengan kadar fenolik total \& vitamin C. Agritech, 33(3), 324-333. https://doi.org/10.22146/AGRITECH.9555

Chan, G. C.-F., Cheung, K.-W., \& Sze, D. M.-Y. (2013). The immunomodulatory \& anticancer properties of propolis. Clinical Reviews in Allergy \& Immunology, 44(3), 262-273. https://doi.org/10.1007/s12016-012-8322-2

Hariyanto, R. A. B. (2017). Penentuan Kandungan Fenolik, Flavonoid \& Aktivitas Antioksidan Ekstrak Propolis Trigona Sp. Surabaya: ultas Matematika \& Ilmu Pengetahuan Alam Institut Teknologi Sepuluh Nopember.

Hasan, A. E. Z., Mangunwidjaja, D., Sunarti, T. C., Suparno, O., \& Setiyono, A. (2014). Investigating the antioxidant \& anticytotoxic activities of propolis collected from five regions of Indonesia \& their abilities to induce apoptosis. Emirates Journal of Food \& Agriculture, 26(5), 390398. https://doi.org/10.9755/ejfa.v26i5.16549

Hasan, A. E. Z., Mangunwidjaja, D., Sunarti, T. C., Suparno, O., \& Setyo, A. (2013). Optimasi ekstraksi propolis menggunakan cara maserasi dengan pelarut etanol $70 \%$ \&amp; pemanasan gelombang mikro serta karakterisasinya sebagai bahan antikanker payudara. Journal of Agroindustrial Technology, 23(1), 13-21.

Indrawati, N., \& Razimin. (2013). Bawang Dayak SI Umbi Ajaib Penakluk Aneka Penyakit. Jakarta Selatan: Agromedia Pustaka.

Jaya, F. (2006). Produk-Produk Lebah Madu \& Hasil Olahannya. Malang: Universitas Brawijaya Press.

Jug, M., Končić, M. Z., \& Kosalec, I. (2014). Modulation of antioxidant, chelating \& antimicrobial activity of poplar chemo-type propolis by extraction procures. LWT - Food Science \& Technology, 57(2), 530537. https://doi.org/10.1016/J.LWT.2014.02.006

Junita, D., Setiawan, B., Anwar, F., \& Muhandri, T. (2017). Komponen gizi, aktivitas antioksidan \& karakteristik sensori bubuk fungsional labu kuning (Cucurbita moschata) \& tempe. Jurnal Gizi \& Pangan, 12(2), 109116. https://doi.org/10.25182/JGP.2017.12.2.109-116

Juspawiza, M. (2013). Potensi Nanopropolis Lebah Madu Trigona Spp \& Lebah Madu Apis Mellifera Sebagai Antioksidan. (Skripsi) Bogor : Fakultas Matematika \& Ilmu Pengetahuan Alam Institut Pertanian.

Khalil, M. I., Moniruzzaman, M., Boukraâ, L., Benhanifia, M., Islam, M. A., Islam, M. N., Gan, S. H. (2012). Physicochemical \& antioxidant properties of algerian honey. Molecules, 17(9), 11199-11215. https://doi.org/10.3390/molecules170911199

Laskar, R. A., Sk, I., Roy, N., \& Begum, N. A. (2010). Antioxidant activity of Indian propolis \& its chemical constituents. Food Chemistry, 122(1), 233-237.

https://doi.org/10.1016/J.FOODCHEM.2010.02.068 
Lukmandaru, G., Vembrianto, K., \& Gazidy, A. A. (2014). Aktivitas antioksidan ekstrak metanol kayu mangifera indica 1., mangifera foetida lour, \& mangifera odorata griff. Jurnal Ilmu Kehutanan, 6(1), 18-29. https://doi.org/10.22146/JIK.3306

Marghitas, L. A., Dezmirean, D. S., Margaona, R., \& Mihai, C. M. (2011). Physico-chemical characterization \& antioxidant activity of transylvanian propolis. Economics, Management, \& Financial Markets, 6(1), 1228-1234.

Miguel, M. G., Nunes, S., Dandlen, S. A., Cavaco, A. M., \& Antunes, M. D. (2010). Phenols \& antioxidant activity of hydro-alcoholic extracts of propolis from Algarve, South of Portugal. Food \& Chemical Toxicology, 48(12), 3418-3423. https://doi.org/10.1016/j.fct.2010.09.014

Neldawati, N. (2013). Analisis Nilai Absorbansi dalam Penentuan kadar flavonoid untuk berbagai jenis daun tanaman obat. PIllar Of Physics, 2(1), 76-83. https://doi.org/10.24036/756171074

Osés, S. M., Pascual-Maté, A., FernándezMuiño, M. A., López-Díaz, T. M., \& Sancho, M. T. (2016). Bioactive properties of honey with propolis. Food Chemistry, 196, 1215-1223. https://doi.org/10.1016/J.FOODCHEM.2015.10.050

Parwata, I. M. O. A., Ratnayani, K., \& Listya, A. (2010). Aktivitas antiradikal bebas serta beta karoten pada madu randu (ceiba petandra) \& madu kelengkeng (nephelium longata 1.). J. Kimia, 4(1), 54-62.

Rismayanti. (2014). Ecology Service Tumbuhan Herba Untuk Lebah Trigona sp. (Skripsi) Bogor: Fakultas Matematika \& Ilmu Pengetahuan Alam Institut Pertanian.
Sabir, A. (2005). Respons inflamasi pada pulpa gigi tikus setelah aplikasi ekstrak etanol propolis (EEP). Dental Journal (Majalah Kedokteran Gigi), $38(2)$, 77-83. https://doi.org/10.20473/j.djmkg.v38.i2.p77-83

Saric, G., Markovic, K., Major, N., Karpan, M., Ursulin-Trstenjak, N., Hruskar, M., \& Vahcic, N. (2012). Changes of antioxidant activity \& phenolic content in acacia \& multifloral honey during storage. Food Technol. Biotechnol, 50(4), 437.

Segueni, N., Zellagui, A., Moussaoui, F., Lahouel, M., \& Rhouati, S. (2016). Flavonoids from Algerian propolis. Arabian Journal of Chemistry, 9(1), 425-428.

https://doi.org/10.1016/J.ARABJC.2011.05.013

Sharma, G. N., Dubey, S. K., Sati, N., \& Sanadya, J. (2011). Phytochemical screening \& estimation of total phenolic content in aegle marmelos seeds. International. International. Journal of Pharmaceutical \& Clinical Research, 3(2), 27-29.

Simone-Finstrom, M., \& Spivak, M. (2010). Propolis \& bee health: the natural history \& significance of resin use by honey bees. Apidologie, 41(3), 295-311. https://doi.org/10.1051/apido/2010016

Suranto, A. (2010). Dahsyatnya Propolis untuk Menggempur Penyakit. Jakarta: Agromedia Pustaka.

Trusheva, B., Popova, M., Bankova, V., Simova, S., Marcucci, M. C., Miorin, P. L., Tsvetkova, I. (2006). Bioactive constituents of brazilian red propolis. Evidence-Based Complementary \& Alternative Medicine: ECAM, 3(2), 249-254. https://doi.org/10.1093/ecam/nel006

Wang, X., Sankarapandian, K., Cheng, Y., Woo, S. O., Kwon, H. W., Perumalsamy, H., \& Ahn, Y.-J. 
(2016). Relationship between total phenolic contents \& biological properties of propolis from 20 different regions in South Korea. BMC Complementary \& Alternative Medicine, 16(1), 1-12. https://doi.org/10.1186/s12906-016-1043-y
Widyasari, R. (2006). Pengujian Asam Semut \& Cuka Kayu dalam Pengendalian Tungau (Varroa destructor) Pada Lebah Madu (Apis mellifera). (Skripsi) Bogor: Fakultas Kehutanan Institut Pertanian.

Winarti, S. (2010). Makanan Fungsional. Yogyakarta: Graha Ilmu. 